\title{
SABER OBJETIVADO E FORMAÇÃO DE PROFESSORES: REFLEXÕES PEDAGÓGICO-EPISTEMOLÓGICAS
}

\author{
Wagner Rodrigues Valente ${ }^{1}$
}

\section{RESUMO}

Este texto busca caracterizar saber objetivado tendo em vista a mobilização dessa noção no debate que trata da constituição dos saberes presentes no ensino e na formação de professores. Para tal, o estudo realiza um inventário sobre os modos diferentes de tratar os saberes presentes no ensino e na formação de professores, levando em consideração mapeamentos brasileiros recentes da pesquisa educacional sobre o tema. Na investigação dos saberes, dois tipos estão presentes: os saberes da ação e os saberes objetivados. Os primeiros constituindo paradigma dominante orientador das pesquisas sobre formação de professores, conforme indicação dos mapeamentos; e os saberes objetivados, sendo tratados por recentes estudos vindos da Universidade de Genebra, na Suíça, de modo a melhor caracterizar como historicamente são configurados os saberes presentes na formação de professores. Como conclusão, o texto argumenta sobre a importância da mobilização de bases teórico-metodológicas que tornem inteligíveis processos e dinâmicas de produção dos saberes profissionais dos professores, colocando no centro das discussões o saber, trazendo para o debate a epistemologia, tratada no campo da formação de professores, problematizando os saberes pedagógicos em termos de processos de objetivação, dando sentido

\footnotetext{
${ }^{1}$ Universidade Federal de São Paulo (Unifesp), Guarulhos/SP, Brasil.
} 
às investigações que visam compreender como se constituem os saberes objetivados em sua articulação com os saberes da ação.

Palavras-chave: formação de professores, saber profissional, epistemologia, saberes da ação, saber objetivado.

\title{
SABER OBJETIVADO Y FORMACIÓN DE PROFESORES: REFLEXIONES PEDAGÓGICAS-EPISTEMOLÓGICAS
}

\section{RESUMEN}

Este texto busca caracterizar el saber objetivado con miras a su movilización en el debate que trata de la constitución de los saberes presentes en la enseñanza y en la formación de profesores. Para ello, el estudio realiza un inventario sobre los diferentes modos de tratar los saberes presentes en la enseñanza y la formación de profesores, tomando en consideración inventarios recientes de la investigación educativa sobre el tema. En la investigación de los saberes, dos tipos están presentes: los saberes de la acción y los saberes objetivados. Los primeros constituyendo paradigma dominante orientador de las investigaciones sobre formación de profesores; y los saberes objetivados, siendo tratados por nuevos estudios venidos de la Universidad de Ginebra, en Suiza. Como conclusión, el texto resalta la importancia de movilizar nuevas bases teóricas y metodológicas para hacer inteligibles los procesos y dinámicas de producción del conocimiento profesional docente, colocando en el centro de las discusiones el conocimiento, llevando al debate la epistemología, tratada en el campo de formación de docentes, problematizando los saberes pedagógicos en términos de procesos de objetivación, dando sentido a las investigaciones que pretenden comprender cómo se constituye el conocimiento objetivado en su articulación con el conocimiento de la acción.

Palabras clave: formación de profesores, saber profesional, epistemología, saberes de la acción, saber objetivado.

\section{OBJECTIFIED KNOWLEDGE AND TEACHER TRAINING: PEDAGOGICAL-EPISTEMOLOGICAL REFLECTIONS}

\begin{abstract}
This text seeks to characterize the objectified knowledge in view of its mobilization in the debate that deals with the constitution of the knowledge present in the teaching and training of teachers. To this end, the study makes an inventory of the different ways of dealing with the knowledge present in teacher education and training, taking into account recent mapping of educational research on the subject. In the investigation of the knowledge, two types are present: the knowledge of the action and the objectified knowledge. The first knowledge constituting the dominant paradigm of research on teacher education; and the objectified knowledge, being treated by new studies coming from the University of Geneva, Switzerland. As a conclusion, the text highlights the importance of mobilizing new theoretical and methodological bases to make processes and dynamics of production of teachers' professional knowledge intelligible, placing at the center of the discussions the knowledge, bringing to the debate the epistemology, treated in
\end{abstract}


the field of formation of teachers, problematizing the pedagogical knowledges in terms of objectification processes, giving meaning to the investigations that aim to understand how the objectified knowledge is constituted in their articulation with the knowledge of the action.

Keywords: teacher training, professional knowledge, epistemology, knowledge of the action, objectified knowledge.

\section{SAVOIR OBJECTIVÉ ET FORMATION DES ENSEIGNANTS: RÉFLEXIONS PÉDAGOGIQUES-ÉPISTEMOLOGIQUES}

\section{RÉSUMÉ}

Ce texte cherche à caractériser le savoir objectivé en vue de sa mobilisation dans le débat qui porte sur la constitution du savoir présent dans l'enseignement et la formation des enseignants. Pour cela, l'étude dresse un inventaire des différentes façons de traiter les savoirs présentes dans l'enseignement et la formation des enseignants, en tenant compte des récents résultats de la recherche pédagogique sur le sujet. Dans l'investigation des savoirs, deux types sont présents: le savoir de l'action et le savoir objectivé. Le premier savoir constituant le paradigme dominant de la recherche sur la formation des enseignants; et les savoir objectivé traitées par de nouvelles études provenant de l'Université de Genève, en Suisse. En conclusion, le texte souligne l'importance de mobiliser de nouvelles bases théoriques et méthodologiques pour rendre intelligibles les processus et les dynamiques de production du savoir professionnel des enseignants, plaçant la connaissance au centre des discussions, apportant au débat l'épistémologie, traitée dans le champ de la formation des enseignants, problématisant les connaissances pédagogiques en termes de processus d'objectivation, donnant un sens à la recherche qui cherche à comprendre comment le savoir objectivé se constitue dans son articulation avec le savoir de l'action.

Mots-clés: formation des enseignants, connaissances professionnelles, épistémologie, savoir de l'action, savoir objectivé. 


\section{INTRODUÇÃO}

No âmbito de pesquisas interessadas em analisar a formação profissional do professor, a discussão sobre o saber é algo basilar. No caso de nosso grupo de pesquisa, que tem interesse na formação do professor que ensina matemática, o tema está presente de modo incisivo. Possivelmente isso também ocorra para as demais áreas disciplinares. Há, por certo, o interesse delas em tratar da formação dos professores que irão atuar na Educação Básica. Em nosso caso, mais especificamente, intenta-se conhecer como historicamente vem sendo dada resposta para a questão: Que matemática deve constituir o saber profissional do professor que ensina matemática?

Os saberes envolvidos na formação dos futuros docentes, saberes fundamentais que deverão fazer parte da sua formação profissional, nos últimos tempos, podem ser considerados de diversos modos. Interessa-nos, neste texto, aquele cunhado como saber objetivado. Assim sendo, este estudo tem por objetivo melhor precisar, caracterizar, saber objetivado tendo em vista a sua mobilização no debate que trata da constituição dos saberes presentes no ensino e na formação de professores.

Pela própria natureza do tipo de pesquisa que o grupo realiza - pesquisas de cunho histórico -, não caberia, de início, pura e simplesmente, definir saber objetivado para, em seguida, utilizar essa conceituação. Antes, será necessário compreender o imperativo de levar em conta tal expressão, no que toca às pesquisas sobre o saber profissional do professor, sobre o saber profissional do professor que ensina matemática. Tendo isso em vista, o texto busca contemplar dois objetivos: de um lado, analisar, mesmo que de modo um tanto breve, a emergência do conceito de saber objetivado e, de outro, tecer considerações sobre a sua importância na análise da constituição do saber profissional do professor, do professor que ensina matemática.

Tentemos iniciar pelo início... Problematizar saberes, realizar uma discussão sobre saberes, leva-nos à epistemologia. 


\section{A EPISTEMOLOGIA, UM MONOPÓLIO DA FILOSOFIA?}

Este subtítulo é tradução literal do título do capítulo escrito por Yves Cusset na obra "Épistémologie, savoirs et champs disciplinaires: questions d'apprentissage" 2 (MARIN; SAVATOVSKY, 2013). O estudo é guiado pela questão: onde a epistemologia tem lugar na formação de professores? (CUSSET, 2013, p. 103). Para melhor dar sentido a esta interrogação, o autor, em seguida, pontua o que os estudos entendem por epistemologia:

uma disciplina metacognitiva dita como transcendental que se interessa pelas condições de instituição de uma ciência em particular ou de um saber em geral, e que emana das ciências instituídas, a partir do momento em que elas lançam sobre si mesmas um olhar reflexivo e crítico, algo que pomposamente poderíamos dizer tratar-se de uma autorreflexão da ciência (CUSSET, 2013, p. 103, tradução nossa).

O desenvolvimento do capítulo e esta caracterização da epistemologia leva o autor a verificar que, na formação de professores franceses, respondendo à questão inicialmente formulada, a epistemologia tem lugar no final da licenciatura, na disciplina de filosofia (CUSSET, 2013, p. 105). Isso quer dizer, ao fim e ao cabo, na análise de Cusset, que nenhuma reflexão epistemológica é realizada levando-se em consideração interrogações sobre as disciplinas escolares, por exemplo. Estabelece-se, dessa maneira, uma dicotomia que aparta de um lado a reflexão pedagógica e de outro a epistemológica. O que acaba reafirmando a epistemologia como um monopólio da filosofia no âmbito da formação de professores. Tal constatação está, segundo o autor, em desacordo com o desenvolvimento das ciências sociais, a partir do início do século XX (CUSSET, 2013, p. 106). A institucionalização das humanidades científicas 3

\footnotetext{
2 “L'épistémologie, un monopole de la philosophie?" - capítulo escrito por Cusset em obra dirigida por Brigitte Marin e Dan Savatovsky.

3 Para o caso brasileiro, o contexto de emergência das humanidades científicas pode ser lido no texto de Valente (1999).
} 
desde esse tempo fornece instrumentos a uma discussão epistemológica para além do âmbito da filosofia, mostrando que a partir de então, a epistemologia, via ciências sociais, poderá fazer surgir e colocar às claras os interesses que presidem o processo de seleção e organização das disciplinas escolares face às ciências instituídas (CUSSET, 2013, p. 106). O autor vai além, ao alertar para o fato de que:

\begin{abstract}
dar exclusividade do ensino de epistemologia à filosofia é também correr o risco de negligenciar a interação entre as formas de transmissão e constituição de um saber instituído como disciplina (...) pois o campo das disciplinas escolares raramente se inscreve no das ciências instituídas; e as suas modificações mais se justificam em razão das exigências internas de transmissão e menos pelas mudanças externas vindas das ciências (CUSSET, 2013, p. 107-108 tradução nossa).
\end{abstract}

Analisada a situação francesa, do papel e posição assumidos pela epistemologia na formação de professores, tem-se que a sua presença se dá no âmbito da filosofia, como mencionado. E que essa pertença toma exclusivamente as ciências instituídas e não promove uma reflexão epistemológica do ponto de vista da formação do profissional para a docência. O futuro professor, no curso de filosofia, verá as ciências, os campos já consagrados do saber, tendo em conta uma clássica visão de que a epistemologia trata do "estudo crítico dos princípios, das hipóteses e dos resultados dos diferentes campos científicos" (CUSSET, 2013, p. 104). Assim, depreende-se que nada levará o professorando a questionar as bases dos saberes profissionais, dos saberes com os quais irá lidar no ofício da docência. Tais saberes estão alijados dos campos científicos consagrados e não ganham lugar na discussão epistemológica.

O questionamento do monopólio da filosofia, no trato da epistemologia, no âmbito da formação de professores, gera um rol de necessidades postas à própria formação dos docentes. Necessidades estas ligadas à análise dos saberes envolvidos na formação para a docência. 
Dessa forma, ao encerrar o capítulo que problematiza o papel da epistemologia na formação de professores Yves Cusset inventaria um conjunto de contribuições que a discussão epistemológica pode dar à formação de professores. Diz ele ser importante:

\begin{abstract}
que os futuros professores sejam formados por uma epistemologia não como filósofos, mas como pedagogos, de modo a melhor considerar a articulação, tanto de um ponto de vista histórico como metodológico e cognitivo, entre paradigmas científicos e modelos de aprendizagem, entre instituição e desenvolvimento de uma ciência e delimitação de uma disciplina escolar, entre formas de transmissão e vulgarização científica, tendo por objetivo também perseguir uma epistemologia crítica capaz de fazer surgir as resistências que a instituição escolar pode opor, por meio dos programas de ensino e seus modelos transmissíveis, às transformações externas da ciência [...] (CUSSET, 2013, p. 111, tradução nossa).
\end{abstract}

Na mesma obra organizada por Brigitte Marin e Dan Savatovsky, em que está presente o texto escrito por Yves Cusset, há outro capítulo, escrito por Alain Bernard, que antecede o estudo sobre o monopólio da filosofia no trato da epistemologia na formação de professores. Intitula-se "Formar os futuros professores pela história das disciplinas escolares” (BERNARD, 2013). Já pelo título, vê-se que melhor teria sido colocá-lo posteriormente ao capítulo de Cusset, pois Bernard trata justamente do papel importante que tem a abordagem sobre as disciplinas escolares na formação de professores.

Reafirmando o que diz Cusset, Bernard explicita a importância de problematizar a existência de disciplinas escolares na formação do futuro docente:

um ensino de história e de epistemologia das disciplinas escolares é necessário se queremos convidar os estudantes, tenham eles ou não uma experiência de ensino, a uma dada forma de reflexão verdadeiramente útil para a prática e para o seu desenvolvimento (BERNARD, 2013, p. 26, tradução nossa). 
O texto de Bernard segue e, em síntese, trata da mesma problemática abordada por Cusset: a necessidade de formar o professor por meio de uma discussão epistemológica que coloque em cena as matérias e disciplinas escolares.

As contribuições desses autores franceses revelam-se importantes quando o tema para debate focaliza o saber profissional do professor, do professor que ensina matemática. Afinal de contas, já de há muito tempo circula pelo nosso país um texto que vem sendo muito utilizado no debate que toca o saber escolar: "História das disciplinas escolares: reflexões sobre um campo de pesquisa” de André Chervel, publicado em 1990, em língua portuguesa. Tal estudo, de modo inovador, mostra-nos um fértil veio de pesquisa para abordar as “disciplinas escolares", modo como o saber se apresenta ao professor, objeto e ferramenta para o ofício docente.

Valente (2013), no mesmo ano em que Brigitte Marin e Dan Savatovsky organizam obra com discussões epistemológicas relativas à Educação, escreve o artigo intitulado "O lugar da matemática escolar na Licenciatura em Matemática”. Nele, o autor aborda a necessidade da inclusão, na formação de professores, de uma reflexão sobre a matemática escolar, ferramenta e objeto de trabalho do professor. Naquela altura, pondera que:

O entendimento da construção histórica da matemática escolar não ocorre, por certo, como vulgarização da Matemática, em termos de transposições didáticas, como sustenta o ferramental teóricometodológico vindo dos estudos da Didática da Matemática. Assim, há necessidade de aprendizagem da construção histórica de produção dos saberes elementares matemáticos. Ela leva ao processo de dar sentido aos conteúdos que são ensinados na escola elementar. Por que a escola básica ensina o que ensina em matemática? Essa parece ser a questão central. Colocar o professorando em situações de desequilíbrio, onde o saber matemático das disciplinas da grade de formação do licenciando não dá conta de explicar as razões da existência ou ausência de temas matemáticos no rol das atividades matemáticas presentes na prática do professor, poderá levá-lo à reconstrução dos saberes elementares em termos historicamente sustentáveis (VALENTE, 2013, p. 950). 
Desse modo, eleger como tema de discussão as disciplinas escolares na formação de professores coloca a instituição escolar e o trabalho docente noutro patamar em termos dos saberes. Afasta a ideia de que a escola é lugar submisso de transmissão de saberes elaborados fora dela. Dá sentido, assim, ao debate epistemológico tratado no âmbito do ensino, via formação de professores. $\mathrm{O}$ tema, dessa forma, não será monopólio da filosofia, voltado tão somente para as disciplinas científicas universitárias, classicamente já estabelecidas.

O questionamento epistemológico inscrito na formação dos professores deveria, como sugerem os autores mencionados anteriormente, abordar as disciplinas escolares e suas relações com as disciplinas científicas, ou campos científicos disciplinares. Nessa problematização caberia analisar como o modo disciplinar se organiza, sistematiza os saberes. E como isso ocorre, também, no meio escolar. Como as disciplinas objetivam os saberes, dão a eles a possibilidade de que sejam comunicáveis, transmissíveis, objetos e ferramentas a estarem presentes na formação de professores e também no ensino escolar4.

Nas lides da docência, os professores realizam o seu trabalho por meio das matérias ou disciplinas escolares. As matérias geralmente consideradas para os primeiros anos escolares; as disciplinas, para a continuidade pós anos iniciais. Com elas - matérias ou disciplinas, os docentes mobilizam saberes objetivados. E, assim, chegamos ao ponto de tratar, neste texto, de modo mais preciso o significado de saber objetivado.

\footnotetext{
4 Para uma discussão mais ampla sobre o tema, leia-se a obra organizada por Jean Boutier, JeanClaude Passeron e Jacques Revel intitulada Qu'est-ce qu'une discipline?
} 


\section{SABER OBJETIVADO}

A princípio, a expressão saber objetivado parece constituir um pleonasmo. Os saberes são objetivados. Isso quer dizer que eles não se expressam como algo subjetivo, ligados a um contexto, a uma situação particular do sujeito. Os saberes são objetivados, "vivem para fora dos sujeitos" de modo a não haver dificuldade na sua comunicação e utilização. Não são próprios de uma particularidade que apresente empecilhos para o seu consumo: não são subjetivos! Assim, os saberes mostram-se como discursos sistematizados, prontos para serem mobilizados, com capacidade para circularem. São comunicáveis de modo a que se possa deles fazer uso e apropriação em diferentes contextos. Mas, caberia, mesmo que brevemente, verificar como a expressão saber objetivado torna-se inicialmente um pleonasmo, para deixar de sê-lo tempos depois.

Tome-se, na história, a relação social travada entre o artesão e o discípulo aprendiz. Relativamente ao saber, o acento é colocado na transmissão de um saber-fazer. Neste caso, aprender não é distinto de fazer: "o tempo da prática é confundido com o tempo da aprendizagem" (VICENT; LAHIRE; THIN, 2001, p. 24). No dizer desses mesmos autores:

\footnotetext{
Nas formações sociais em que, em nenhum momento, o saber é separado das práticas sociais do grupo, mas se transmite na prática, no âmago da prática, numa participação, numa mimese e numa identificação, o que é feito (dizendo), o que existe e o que é dito (fazendo, agindo) é absolutamente indissociável (Ibid., p. 27).
}

No que concerne à educação, à formação, os saberes parecem estar no centro do surgimento de uma nova relação social, que coloca em contato um "mestre" e um "aluno" definindo o que entendemos por "relação pedagógica". Nessa relação, o saber terá natureza distinta daquela existente entre artesão e discípulo aprendiz. 
Com o surgimento da escola, apartada da vida cotidiana, como espaço em separado das urgências do dia-a-dia, na constituição da relação pedagógica, o saber mostra-se distinto do fazer. E esse saber objetiva-se na produção de matérias e disciplinas escolares. Assim, os mestres na relação pedagógica não mais se relacionam com os discípulos em termos de subjetividades, de uma relação pessoa a pessoa, mas de uma submissão de mestres e alunos a regras impessoais, a saberes postos nas matérias e disciplinas a serem ensinadas.

\begin{abstract}
A pedagogia (no sentido restrito da palavra) se articula a um modelo explícito, objetivado e fixo de saber a transmitir. Os saberes objetivados, explicitados, fixos, que se pretende transmitir colocam um problema historicamente inédito quanto ao modo de transmissão do saber. Trata-se de fazer interiorizar, pelos alunos, determinados saberes que conquistaram sua coerência na/pela escrita (através de um trabalho de classificação, divisão, articulação, estabelecimento de relações, comparação, hierarquização etc.) (VINCENT; LAHIRE; THIN, 2001, p. 29).
\end{abstract}

Desse modo, saber, na relação pedagógica, torna-se sinônimo de discurso sistematizado, objetivado. E "saber objetivado", nesse contexto, vem a significar um pleonasmo...

No entanto, é possível dizer que, nos últimos vinte, trinta anos quase, em termos da pesquisa educacional, em especial, aquela relativa à formação de professores, no Brasil, há uma ênfase no que se refere à existência de um "saber não objetivado", uma tendência presente até a atualidade de considerar, sobretudo para o debate da profissão docente, os saberes vindos da ação.

Os saberes da ação constituem referência trazida a partir de meados dos anos 1990 ao campo das ciências da educação, sobretudo, por Barbier (1996) (AVENIER; SCHMITT, 2007).

Barbier, na Introdução da obra que dirige - Savoirs théoriques et savoirs d'action - menciona os caminhos que levam à caracterização dos saberes da ação: 
[...] no domínio da formação e do desenvolvimento, constatamos evoluções importantes que parecem orientar-se de modo próximo: desenvolvimento de formações integradas à ação e ao trabalho, utilização explícita de processos de escrita, de formalização e de pesquisa com vistas à formação e ao desenvolvimento, construção de dispositivos que articulam aquisições em situação de formação e aquisições em situação de trabalho, individualização de percursos etc. (BARBIER, 2014, p. 3, tradução nossa).

Tais percursos, avalia Barbier, mostram que há um ponto comum entre eles que é dado pela suposição de que aprendizes e os já formados desenvolvem uma atitude intelectual sobre e a partir das ações, ou de situações concretas, em que estão engajados, tendo por finalidade a produção de novos saberes e novas competências (BARBIER, 2014, p. 3). Aí está! Como se vê, a caracterização de saber é também utilizado em termos de situações concretas, ligadas ao sujeito que experencia e, ao mesmo tempo, produzem tais saberes. Assim,

O ato do trabalho torna-se ato de formação quando ele é acompanhado de uma atividade de análise, de estudo ou de pesquisa sobre ele mesmo. A produção de saberes pelo aprendiz é então utilizada como uma ferramenta direta de produção de competência [...] (BARBIER, 2014, p. 3, tradução nossa).

Essa discussão relativa à produção de saberes pela ação levou à categorização de tipos de saberes diferentes. Desse modo, os teóricos do campo educacional buscaram uma classificação: saberes da ação e saberes teóricos.

Os saberes da ação considerados como "saberes escondidos”, saberes da experiência, saberes informais, vindos de competências adquiridas na ação e pela ação. Os saberes teóricos tradicionalmente vistos como saberes disciplinares, quer sejam tomados como saberes disciplinares da pesquisa ou do ensino (BARBIER, 2014, p. 4, tradução nossa).

De modo mais elaborado, Barbier identifica duas zonas de significados para os saberes, duas zonas semânticas: uma dada pelos saberes objetivados e outra a dos savoirs détenus, isto é, dos saberes que o sujeito detém, ou saberes 
incorporados pelo sujeito. Explicando melhor cada uma delas, diz o autor, discorrendo sobre os saberes objetivados:

o campo dos saberes objetivados pertence à mesma zona semântica da cultura, das regras, dos valores. Esta zona refere-se provavelmente a realidades que têm o estatuto de representações ou de sistemas de representações dando lugar a enunciados proposicionais e tendo por objeto uma valorização social sancionada por uma atividade de transmissão-comunicação. Essas realidades distinguem-se daqueles que as enunciam ou daqueles que delas se apropriam. Elas são conserváveis, cumulativas e apropriáveis. No âmbito dessa zona semântica, os saberes objetivados podem ser definidos como enunciados de proposições sendo objeto de um julgamento social que se situa no registro da verdade ou da eficiência. Eles podem mesmo ser considerados duplamente como enunciados: de uma parte eles formalizam uma representação do real (eles dizem 'alguma coisa' sobre o real), de outra parte eles enunciam uma correspondência, uma ligação entre essa representação e o objeto representado (a noção de verdade é a afirmação de uma correspondência) (BARBIER, 2014, p. 9, tradução nossa).

Na caracterização de outro campo semântico, o dos saberes da ação, o autor debruça-se sobre os saberes que o sujeito detém, para tais saberes ligam-se capacidades, conhecimentos, competências, atitudes, profissionalidades. Dessa forma, neste outro contexto, saber objetivado deixa de ser um pleonasmo...

\section{SABERES DA AÇÃO E A PESQUISA DOS SABERES PROFISSIONAIS DO PROFESSOR}

As implicações da conceituação dos saberes, em termos de saberes objetivados e saberes da ação para a pesquisa, para a pesquisa educacional e, em particular, para as pesquisas sobre a formação de professores, professores que ensinam matemática, nos parecem fundamentais. Esse movimento que coloca ênfase nos saberes da ação vem se constituindo como verdadeiro paradigma para as investigações do campo educacional em épocas mais recentes. Tal fato poderá 
ser constatado tendo-se em conta a elaboração, em tempos atuais, de inventários de pesquisas na educação e na educação matemática sobre formação de professores.

No que diz respeito à formação de professores de maneira geral, são exemplos dessas sínteses as pesquisas realizadas por Marli André no que toca às tensões e perspectivas de pesquisas sobre formação de professores (ANDRÉ, 2011); também aquelas elaboradas por Bernadete Gatti relativas às pesquisas sobre a formação inicial de professores para a escola básica (GATTI, 2014). Somam-se a esses trabalhos, os estudos realizados por Libânia Xavier sobre a construção da profissão docente (XAVIER, 2014) e, mais recentemente, o texto de Itale Cericato que mostra uma revisão bibliográfica de estudos sobre o mesmo tema (CERICATO, 2016).

Em relação à formação de professores que ensinam matemática, destacam-se pesquisas como as que vêm sendo realizadas, desde 2002, pelo Grupo de História Oral e Educação Matemática (Ghoem), por meio de projeto que vem sendo desenvolvido sistemática e continuadamente, no qual se tem buscado elaborar um mapeamento (histórico) sobre a formação e atuação dos professores de Matemática no Brasil (GARNICA; FERNANDES; SILVA, 2011), e pelo do Grupo de Estudos e Pesquisas sobre Formação de Professores de Matemática (GEPFPM), cujos primeiros resultados foram publicados no livro "Mapeamento da pesquisa acadêmica brasileira sobre o professor que ensina matemática: período 2001-2012" (FIORENTINI; PASSOS; LIMA, 2016).

Esses inventários mostram que os trabalhos sobre formação de professores, sobre didática, sobre saberes profissionais dos docentes vêm mobilizando os saberes da ação. Como se disse, algo paradigmático posto nestes últimos trinta anos. Ao que parece, tais pesquisas tendem a desinteressar-se dos saberes da formação inicial de professores, considerada engessada, restrita às disciplinas que pouco contribuiriam para a formação profissional, herdeiras de visões conservadoras relativamente ao trabalho docente. A ênfase maior dada pelos estudos refere-se à formação continuada de professores, lugar próprio para 
a discussão e apropriação dos saberes da ação. Também cabe pontuar que muitos estudos realizados na perspectiva dos saberes da ação têm lançado mão de narrativas. E, há, na Educação Matemática, uma grande ênfase no uso delas tendo em consideração a formação de professores que ensinam matemática. As narrativas são transcritas, textualizadas, como produções dos sujeitos, verdadeiros relatos de saberes da ação colocados pela perspectiva pessoal de atuação profissional dos docentes. De todo modo, a ênfase na subjetividade ganha destaque nas pesquisas e esta subjetividade, em termos de saber, tem expressão por meio dos saberes da açãos.

Relativamente às ponderações anteriores, que consideram fundamental trazer a discussão epistemológica à formação de professores, o novo paradigma parece sujeitar-se às necessidades urgentes da prática docente, fazendo-nos lembrar, mesmo que com todas as ressalvas, a relação artesão-aprendiz: aprender fazendo. Parece não haver nos estudos um olhar para o tensionamento existente entre as relações que historicamente se estabelecem entre disciplinas científicas e disciplinas escolares. Numa das sínteses dos inventários sobre as pesquisas que analisam o saber profissional do professor é possível ler:

As pesquisas desenvolvidas por esses autores demonstraram, entre outros aspectos, que os saberes docentes são temporais, plurais, e heterogêneos, personalizados e situados e, ainda, carregam consigo as marcas do seu objeto, que é o ser humano. Com isso, os autores contrapõem o caráter subjetivo do trabalho docente aos ideais de racionalidade e objetividade que marcaram, durante muito tempo, as orientações de alguns especialistas em planos e políticas dirigidos aos professores (XAVIER, 2014, p. 831).

Dessa forma, o novo paradigma dos saberes da ação tende a uma rejeição tanto das disciplinas classicamente estabelecidas, quanto da elaboração histórica das disciplinas escolares.

\footnotetext{
5 Um exemplo significativo de estudos na Educação Matemática é a produção do Grupo de História Oral da Educação Matemática (Ghoem).
} 
De outra parte, em alguma medida, é possível dizer que esses mesmos inventários sobre as pesquisas relativas à formação de professores e de professores que ensinam matemática vêm apontando certa insatisfação com essa perspectiva de investigação. E isso se manifesta justamente pelos limites que os saberes da ação encerram: a dificuldade posta para a sua sistematização e formalização com vistas à sua transmissão-comunicação-circulação-apropriação.

\footnotetext{
Embora essas pesquisas tenham analisado a formação do formador de professores de Matemática, produzindo resultados sobre esse processo, é possível avançar na direção de delimitar saberes, conhecimentos específicos do formador, necessários à sua atividade profissional; e, ainda, analisar em que medida se diferenciam dos saberes do professor que ele forma. Consideramos, portanto, a necessidade de pesquisas que tomem como objeto de investigação os conhecimentos de que o formador necessita para seu exercício profissional, principalmente para formar professores de Matemática, rompendo os silêncios que prevalecem nas licenciaturas em Matemática (COURA; PASSOS, 2017, p. 21).
}

Tal citação é emblemática: há necessidade de "delimitar saberes, conhecimentos específicos [...]". Noutros termos: está posto o imperativo de objetivação dos saberes para a formação profissional.

\section{OS SABERES OBJETIVADOS E AS NOVAS PERSPECTIVAS PARA A FORMAÇÃO DE PROFESSORES}

À vista desses limites e da necessidade de formulação de propostas para a formação inicial de professores, novos estudos vêm sendo elaborados, agora na perspectiva de investigações que intentam compreender como os saberes objetivados articulam-se com os saberes da ação. Já no próprio livro organizado por Jean-Marie Barbier há propostas que apontam para a necessidade de se 
considerar essa articulação desses saberes de natureza diversa ${ }^{6}$.

Mais recentemente, a Equipe de Pesquisa em História das Ciências da Educação (Erhise) da Universidade de Genebra, sem considerar ou dar ênfase nos saberes da ação, vem encetando pesquisas que, do ponto de vista da formação de professores, leva em conta os saberes a ensinar e os saberes para ensinar. Em breve síntese, os primeiros articulados aos campos disciplinares, configurandose como objetos de ensino; os segundos, constituídos como ferramentas de trabalho do professor. Ambos tratados como saberes objetivados. Ao que parece, a caracterização desses saberes como objetivados visa melhor explicitar essas categorias da pesquisa do grupo suíço. De outra parte, tais investigações voltamse para a análise de como se articulam esses dois tipos de saberes objetivados. E essa análise é de cunho sócio-histórico.

As contribuições teóricas da Erhise permitem que consideremos a existência, ao longo do tempo, de processos de objetivação. Tais processos resultam na constituição dos saberes objetivados. Envolvem tempo relativamente longo, situações de decantação, de estabilização, de consensos sobre determinados saberes que vão ganhando formas sistematizadas para se tornarem referência à formação de professores, em termos da constituição de matérias de ensino, de disciplinas escolares e científicas. Ter em conta processos de objetivação leva-nos a considerar saberes "ainda não objetivados", por exemplo, saberes da ação. Mais precisamente, coloca-nos o desafio de estudar historicamente como se articulam, ao longo do tempo, esses dois saberes: objetivados, representando herança sedimentada de saberes comunicáveis passíveis de apropriação; e saberes da ação, evidenciados na prática pedagógica dos professores numa dada época histórica, transcritos sob formas diversas, chegando até a atualidade por meio de transcrições de relatos de experiências de práticas, de memórias da docência, de anotações em cadernos de classe e de

\footnotetext{
${ }^{6}$ Este é o caso, por exemplo, do estudo de Mialaret (2014) que conclui afirmando que "[...] a questão fundamental atual é a de saber como os diferentes tipos de saber se articulam e como eles podem fecundarem-se uns aos outros [...]" (p. 186).
} 
alunos etc.

No estudo da articulação dos saberes, tendo em vista a produção de saberes objetivados, os complexos processos de objetivação colocam em destaque o papel histórico da emergência da expertise pedagógica7. A criação e ação dos experts no campo pedagógico e o seu papel na objetivação dos saberes ${ }^{8}$.

Captar o movimento de sistematização de saberes da ação, em processo histórico, de modo a que se tenha, para uma dada época escolar, a constituição de saberes objetivados em matérias e disciplinas escolares é o desafio que pesquisas recentes têm enfrentado 9 . Tais investigações são fundamentais para a compreensão das dinâmicas de elaboração do saber profissional da docência. Elas colocam em relação os saberes instituídos, objetivados face àqueles saberes $d a$ ação. E, nessa relação, resultam novos saberes objetivados, fixados em normas oficiais, em programas de ensino, em livros e manuais pedagógicos, dentre outros documentos, vistos como referências, num dado tempo, para o trabalho docente.

\section{CONSIDERAÇÕES FINAIS}

Os estudos que vêm sendo desenvolvidos no âmbito do projeto coletivo "A matemática na formação de professores e no ensino: processos e dinâmicas de produção de um saber profissional, 1890-1990", por nosso grupo de pesquisa, apropriando-se do ferramental teórico-metodológico trazido pelo grupo suíço, tratam a matemática na formação de professores em termos de uma matemática a ensinar e de uma matemática para ensinar. A primeira, resultante de

\footnotetext{
7 Expertise entendida como: "[...] uma instância, em princípio reconhecida como legítima, atribuída a um ou a vários especialistas - supostamente distinguidos pelos seus conhecimentos, atitudes, experiências -, a fim de examinar uma situação, de avaliar um fenômeno, de constatar fatos" (HOFSTETTER; VALENTE, 2017, p. 38).

8 Para um aprofundamento dessa temática leia-se o Capítulo 2 do livro (HOFSTETTER; VALENTE, 2017). De outra parte, no Brasil, já há alguns estudos que evocam o papel dos experts na produção de saberes, como os trabalhos de Villela et al. (2016) e, também, Morais (2017).

9 Citem-se os estudos desenvolvidos por Oliveira (2017) e Pinheiro (2017), dentre alguns outros.
} 
processos de elaboração que tomam por referência o campo disciplinar, a matemática; a segunda, tendo em vista os saberes do campo pedagógico, as disciplinas das ciências da educação.

Com isso, instala-se um novo campo de investigações que remete ao estudo, em perspectiva histórica, dos processos de elaboração de cada uma dessas matemáticas, bem como a investigação das dinâmicas de articulação entre a matemática a ensinar e a matemática para ensinar.

Essas novas bases teórico-metodológicas mobilizadas para tornar inteligíveis processos e dinâmicas de produção dos saberes profissionais dos professores e, em especial, saberes profissionais do professor que ensina matemática coloca no centro das discussões o saber, traz para o debate a epistemologia, tratada no campo pedagógico, problematiza os saberes pedagógicos em termos de processos de objetivação, dá sentido às investigações que visam compreender como se constituem os saberes objetivados em sua articulação com os saberes da ação.

\section{REFERÊNCIAS}

ANDRÉ, Marli E. D. A. A produção acadêmica sobre formação de professores: um estudo comparativo das dissertações e teses defendidas nos anos de 1990 e 200o. Revista Brasileira de Pesquisa sobre Formação de Docente, Belo Horizonte, Autêntica, v. 1, n. 1, p. 41-56, ago./dez. 2009. Disponível em: http://formacaodocente.autenticaeditora.com.br/artigo/exibir/1/7/3. Acesso em: 25 mar. 2017.

ANDRÉ, Marli E. D. A. Pesquisas sobre formação de professores: tensões e perspectivas do campo. In: FONTOURA, Helena Amaral; SILVA, Marco (org.).

Formação de professores, culturas: desafios à Pós-graduação em Educação em suas múltiplas dimensões. E-book online. In: ENCONTRO DE PESQUISA EM EDUCAÇÃO DA REGIÃO SUDESTE, 10., 2011, Anped Sudeste. Disponível em: http://www.fe.ufrj.br/anpedinha2011/sobre.html. p. 24-36. Acesso em: 6 mar. 2017. 
AVENIER, Marie-José; SCHMITT, Christophe. La construction de savoirs pour l'action. Paris: L’Harmattan, 2007.

BARBIER, Jean-Marie. Savoirs théoriques et savoirs d'action. Paris: PUF, 2014 [1996].

BERNARD, Alain. Former les futurs enseignats à l'histoire des disciplines scolaires. In: MARIN, Brigitte; SAVATOVSKY, Dan (dir.). Épistémologie, savoirs et champs disciplinaires: questions d'apprentissage. Conférences de Consensus de l'IUFM de l'académie de Créteil - Université Paris-Est Créteil, Créteil, n. 4, p. 15-27, 2013.

BOUTIER, Jean; PASSERON, Jean-Claude; REVEL, Jacques (ed.). Qu'est-ce qu'une discipline? Paris: Éditions de l'EHESS, 2006.

CERICATO, Itale Luciane. A profissão docente em análise no Brasil: uma revisão bibliográfica. Rev. Bras. Estud. Pedagog. [online], v. 97, n. 246, p. 273-289, 2016. Disponível em: http://dx.doi.org/10.1590/S21766681/373714647. Acesso em: 17 mar. 2017.

CHERVEL, André. História das disciplinas escolares: reflexões sobre um campo de pesquisa. Teoria \& Educação, n. 2, p. 177-229, 1990.

COURA, Flávia Cristina Figueiredo; PASSOS, Cármen Lúcia Brancaglion. Estado do conhecimento sobre o formador de professores de Matemática no Brasil. Zetetiké, Campinas/SP, v. 25, n. 1, 2017.

CUSSET, Yves. L'épistémologie, un monopole de la philosophie? In: MARIN, Brigitte; SAVATOVSKY, Dan (dir.). Épistémologie, savoirs et champs disciplinaires: questions d'apprentissage. Conférences de Consensus de l'IUFM de l'académie de Créteil - Université Paris-Est Créteil, Créteil, n. 4, p. 103-112, 2013.

FIORENTINI, Dario; CRECCI, Vanessa Moreira; NACARATO, Adair Mendes. Estudos do estado da arte da pesquisa sobre o professor que ensina matemática. Dossiê Temático. Zetetiké, Campinas/SP, v. 25, n. 1, 2017.

FIORENTINI, Dario; GRANDO, Regina Célio; LIMA, Rosana Catarina Rodrigues de; CRECCI, Vanessa Moreira; COSTA, Marina Carravero. O professor que ensina matemática como campo de investigação: um estudo do estado da arte. In: ENCONTRO NACIONAL DE EDUCAÇÃO MATEMÁTICA (SBEM), 12., 2016, São Paulo. Anais [...]. São Paulo: Sociedade Brasileira de Educação Matemática (SBEM), 2016. Disponível em: http://sbempe.cpanelo179.hospedagemdesites.ws/enem2016/anais/pdf/8102_ 
4251_ID.pdf. Acesso em: 25 out. 2016.

FIORENTINI, Dario; PASSOS, Cármen Lúcia Brancaglion; LIMA, Rosana

Catarina Rodrigues de (org.). Mapeamento da pesquisa acadêmica

brasileira sobre o professor que ensina matemática: período 20012012. Campinas: FE/Unicamp, 2016. Disponível em:

https://www.fe.unicamp.br/pf-fe/pf/subportais/biblioteca/fev-2017/e-bookmapeamento-pesquisa-pem.pdf. Acesso em: 6 mar. 2017.

GARNICA, Antonio Vicente Marafioti; FERNANDES, Déa Nunes; SILVA, Heloisa da. Entre a amnésia e a vontade de nada esquecer: notas sobre Regimes de Historicidade e História Oral. Bolema, v. 25, n. 4, p. 213-250, 2011. Disponível em: http://www.redalyc.org/pdf/2912/291223514011.pdf. Acesso em: 25 mar. 2017.

GATTI, Bernardete A. Formação inicial de professores para a educação básica: pesquisas e políticas educacionais. Est. Aval. Educ., São Paulo, v. 25, n. 57, p. 24-54, jan./abr. 2014.

HOFSTETTER, Rita; VALENTE, Wagner Rodrigues (org.). Saberes em (trans)formação: tema central da formação de professores. São Paulo: LF Editorial, 2017.

MEGID, Maria Auxiliadora Bueno Andrade et al. Mapeamento da pesquisa paulista sobre o professor que ensina matemática: aspectos físicos e tendências metodológica e temática. In: FIORENTINI, Dario; PASSOS, Cármen Lúcia Brancaglion; LIMA, Rosana Catarina Rodrigues de (org.). Mapeamento da pesquisa acadêmica brasileira sobre o professor que ensina matemática: período 2001-2012. Campinas: FE/Unicamp, 2016. p. 107-175. Disponível em: https://www.fe.unicamp.br/pf-fe/pf/subportais/biblioteca/fev2017/e-book-mapeamento-pesquisa-pem.pdf. Acesso em: 6 mar. 2017.

MIALARET, Gaston. Savoirs théoriques, savoirs scientifiques et savoirs d'action en éducation. In: BARBIER, Jean-Marie. Savoirs théoriques et savoirs d'action. Paris: PUF, 2014 [1996]. p. 161-187.

MORAIS, Rosilda dos Santos. A produção dos saberes para ensinar e saberes $a$ ensinar: o papel dos experts e o caso da resolução de problemas. In: BERTINI, Luciane de Fátima; MORAIS, Rosilda dos Santos; VALENTE, Wagner Rodrigues. A matemática a ensinar e a matemática para ensinar: novos estudos sobre a formação de professores. São Paulo: LF Editorial, 2017. p. 17-37.

OLIVEIRA, Marcus Aldenisson de. A aritmética escolar e o método intuitivo: um novo saber para o curso primário (1870-1920). 280 f. 2017. Tese 
(Doutorado em Ciências) - Programa de Pós-Graduação em Educação e Saúde na Infância e na Adolescência, Universidade Federal de São Paulo/Unifesp, Guarulhos/SP, 2017.

PINHEIRO, Nara Vilma Lima. A aritmética sob medida: a matemática em tempos da pedagogia científica. 224 f. 2017. Tese (Doutorado em Ciências) Programa de Pós-Graduação em Educação e Saúde na Infância e na Adolescência, Universidade Federal de São Paulo/Unifesp, Guarulhos/SP, 2017.

VALENTE, Wagner Rodrigues. A matemática na formação clássico-literária, tornando-se ensino de cultura geral. Educação Matemática Pesquisa, São Paulo, v. 1, n. 2, p. 34-45, 1999.

VALENTE, Wagner Rodrigues. O lugar da matemática escolar na Licenciatura em Matemática. Bolema, Rio Claro, v. 27, n. 47, 2013. DOI:

http://dx.doi.org/10.1590/So103-636X2013000400012.

VICENT, Guy; LAHIRE, Bernard; THIN, Daniel. Sobre a história e a teoria da forma escolar. Educação em Revista, Belo Horizonte, n. 33, jun. 2001.

VILLELA, Lúcia Maria Aversa et al. Os experts dos primeiros anos escolares: a construção de um corpo de especialistas no ensino de matemática, 1930-1970. In: PINTO, Neuza Bertoni; VALENTE, Wagner Rodrigues (org.). Saberes elementares matemáticos em circulação no Brasil: dos documentos oficiais às revistas pedagógicas, 1890-1970. São Paulo: LF Editorial, 2016. p. $245-287$.

\footnotetext{
WAGNER RODRIGUES VALENTE é professor Livre Docente do Departamento de Educação da Escola de Filosofia, Letras e Ciências Humanas da Universidade Federal de São Paulo (Unifesp), Campus Guarulhos.

E-mail: ghemat.contato@gmail.com

(D) http://orcid.org/0000-0002-2477-6677
}

Recebido em: 30 de outubro de 2017

Aprovado em: 14 de janeiro de 2019 